\title{
Intra-Arterial Verapamil Treatment in Oral Therapy- Refractory Reversible Cerebral Vasoconstriction Syndrome
}

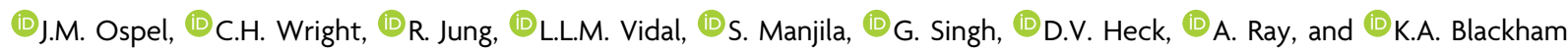

\begin{abstract}
SUMMARY: Reversible vasoconstriction syndrome is a complex of clinical symptoms and angiographic findings, which, while having a mostly benign clinical course, has clinical and imaging overlap with more serious disorders such as vasculitis and aneurysmal SAH and itself includes a minority of patients with fulminant vasoconstriction resulting in severe intracranial complications. Endovascular options for patients with refractory reversible cerebral vasoconstriction syndrome include intra-arterial vasodilator infusion similar to therapy for patients with vasospasm after SAH. To date, only case reports and 1 small series have discussed the utility of intraarterial vasodilators for the treatment of reversible cerebral vasoconstriction syndrome. We report an additional series of 11 medically refractory cases of presumed or proved reversible cerebral vasoconstriction syndrome successfully treated with intra-arterial verapamil infusion. Furthermore, we propose that the reversal of vasoconstriction, as seen on angiography, could fulfill a diagnostic criterion.
\end{abstract}

ABBREVIATIONS: IA = intra-arterial; RCVS = reversible cerebral vasoconstriction syndrome

$\mathbf{R}$ eversible cerebral vasoconstriction syndrome (RCVS) describes a constellation of clinical and angiographic findings that includes severe headache and reversible segmental vasoconstriction of the cerebral arteries, with or without neurologic deficits. Diagnosis is difficult and one of exclusion because the differential diagnosis for sudden severe headache includes both aneurysmal and nonaneurysmal subarachnoid hemorrhage. Moreover, the broad differential diagnosis of vasoconstriction of the cerebral vessels encompasses diverse entities such as primary angiitis of the CNS and atherosclerosis. Numerous inciting factors for RCVS have been described, but the list of triggers continues to grow. ${ }^{1,2}$ Treatment options include medical optimization of risk

Received December 31, 2018; accepted after revision November 16, 2019.

From the Department of Radiology (J.M.O., K.A.B.), Section of Neuroradiology and Interventional Neuroradiology, Basel University Hospital, University of Basel, Basel, Switzerland; Departments of Neurological Surgery (C.H.W.), and Neurosurgery (A.R.), University Hospitals of Cleveland Case Medical Center, Cleveland, Ohio; Department of Diagnostic Radiology and Nuclear Medicine (L.L.M.V.), University of Maryland Medical Center, Baltimore, Maryland; Department of Neurology (R.J.), The Sandra and Malcolm Berman Brain \& Spine Institute, Sinai Hospital of Baltimore, LIfebridge Health, Baltimore, Maryland; Department of Neurosurgery and Neurosciences (S.M.), McLaren Bay Region Hospital, Bay City, Michigan; Department of Radiology (G.S.), Section of Neuroradiology, Newark Beth Israel Medical Center, Newark, New Jersey; and Forsyth Radiological Associates (D.V.H.), Winston-Salem, North Carolina.

Please address correspondence to Johanna Maria Ospel, MD, Department of Radiology, Basel University Hospital, University of Basel, Petersgraben 4, 4051 Basel, Basel, Switzerland; e-mail: johannamaria.ospel@usb.ch; @johanna_ospel; @KBlackhamMD

Indicates article with supplemental on-line table.

http://dx.doi.org/10.3174/ajnr.A6378 factors, corticosteroids, and oral or intra-arterial calcium channel blockers. ${ }^{3}$ If left untreated, RCVS can lead to permanent neurologic disability and even death. ${ }^{4-6}$ Complications such as hemorrhage and stroke are well-documented. ${ }^{1,7}$ In the past decade, on the basis of the experience with treatment of patients with vasospasm secondary to $\mathrm{SAH}$, an endovascular approach using the intra-arterial (IA) infusion of calcium channel blockers in patients with refractory RCVS has emerged, with case reports and a small series of promptly improved vessel caliber and also symptoms. ${ }^{8,9}$ The underlying hypothesis is that the vasoconstriction of RCVS is vasospasm as observed in SAH and that similar treatment approaches will similarly prevent the development of permanent neurologic deficits. In this case series, we present 11 patients with documented or presumed RCVS who presented with or progressed to clinically relevant vasoconstriction and in whom IA treatment with verapamil resulted in clinical and radiographic improvement. A detailed narrative description, including illustrative images, of 3 exemplary patients is provided.

\section{MATERIALS AND METHODS}

Since 2006, the authors have used intra-arterial verapamil as a treatment option in patients with suspected RCVS and clinical deterioration. Individual cases of patients with presumed RCVS who underwent cerebral angiography with intra-arterial administration of verapamil were retrospectively identified through a departmental angiography data base search from 2006-2016 at the University Hospital of Basel, Switzerland; 2006-2016 at 
1 Unusual, acute severe headache of progressive or sudden onset, presenting with or without neurologic focal deficit and/or seizure

2 Benign CSF analysis (protein level, $<80 \mathrm{mg} / \mathrm{dL}$; leukocyte count, $<10 / \mathrm{mm}^{3}$; and normal glucose level)

3 Imaging studies demonstrating 2 different points of vessel narrowing in at least 2 different intracranial arteries

$4 \quad$ Imaging proving absence of intracranial aneurysm/vascular malformation or aneurysmal SAH

5 Reversibility of intracranial vessel narrowing on short-term follow-up evaluation ( $<12$ months)

University Hospitals of Cleveland, Case Medical Center in Cleveland, Ohio; and 2006-2011 at Forsythe Medical Center in Winston-Salem, North Carolina, which identified patients undergoing intra-arterial verapamil infusion for any reason. Inclusion criteria are listed in Table 1 and are based on work by Calabrese, et al. $^{4}$ We interpreted criterion number 5 to include acute reversibility demonstrated as a result of verapamil treatment. Patients treated for vasospasm in the setting of nonaneurysmal (perimesencephalic) subarachnoid hemorrhage were excluded. Institutional board review approval (University Hospitals of Cleveland and Forsythe Medical Center) and individuals' written consent (University Hospital of Basel) were obtained for this multicenter case series. All imaging, clinical records, laboratory results, and treatment and follow-up data were obtained from the electronic medical records and PACS of the hospitals and were reviewed by 2 experienced neurointerventionalists (K.A.B./A.R.) to verify inclusion.

\section{Image Interpretation}

Procedural information and angiographic results were also retrospectively evaluated by 2 experienced neurointerventionalists (K.A.B./A.R.) for confirmation of treatment indications and results. A semiquantitative classification of grade was performed by visually assessing the luminal narrowing compared with the best normal vessel caliber on either the same study or prior cerebral angiograms using the following categories: 1) mild: luminal narrowing of $<30 \%$ of normal caliber; 2 ) moderate: between $30 \%$ and $60 \%$ of normal caliber; and 3) severe: luminal narrowing of $>60 \%$ of normal caliber, similar to the stratification described by Jun et al. ${ }^{10}$ At least 1 segmental focus of at least moderate proximal vasoconstriction or any distal vasoconstriction would indicate the need for intra-arterial treatment. Confirmation of an adequate angiographic response to treatment was defined as a $10 \%-30 \%$ improvement in the most severely constricted vessel caliber.

\section{DSA and IA Verapamil Therapy}

Endovascular treatment was performed using a standard biplane angiographic technique starting with a diagnostic series of both internal carotid arteries and the dominant vertebral artery, with the patient under systemic heparinization. IA verapamil was administered proximally in the affected vascular territory. Verapamil was diluted in saline to a final concentration of $1 \mathrm{mg} / \mathrm{mL}$ and pulseinfused at a rate of $1 \mathrm{~mL} / \mathrm{min}$ through the diagnostic catheter, meaning that $1 \mathrm{~mL}$ of verapamil was manually injected every minute through the side port of a 3-way valve connected to the diagnostic catheter and also to a continuous heparinized saline flush, allowing intermittent flush. The overall dosage was determined by the vasoconstriction degree and distribution; higher doses of verapamil were used in more extensive and more severe vasoconstrictions with a range of
5-20 mg per territory (maximum of $20 \mathrm{mg}$ per vessel and 60-mg total dose per session) as described in the treatment of subarachnoid hemorrhage-induced vasospasm by Jun et $\mathrm{al}^{10}$ and Keuskamp et al. ${ }^{11}$ Due to prolonged procedural times because of the slow infusion rate, treatment was performed with monitored anesthesia care with continuous monitoring of systemic blood pressure, heart rate, respiratory frequency, and arterial oxygen saturation. Repeat images to demonstrate the absence of embolic complications were obtained immediately following injection, and images to demonstrate the vasodilatory response were obtained at a minimum of 10 minutes following the injection. ${ }^{12}$ At the end of the procedure, the patients were admitted to intensive care for blood pressure support and monitoring per protocol for patients with SAH and vasospasm. Patients were monitored clinically and with daily transcranial Doppler sonography.

\section{RESULTS}

Eleven patients with presumed RCVS who underwent IA treatment with verapamil were identified (Table 2 and On-line Table). All patients met the 5 criteria for RCVS (Table 1); 4 patients had ambulatory imaging documentation of complete vasoconstriction resolution, and the remaining patients without ambulatory follow-up had reversibility of the vasoconstriction at the time of treatment. Nine of the identified patients were women, and 2 were men, with a mean age of $38.2 \pm 13.1$ years. Serologic vasculitis work-up including antinuclear antibodies, rheumatoid factor, soluble substance A and soluble substance $\mathrm{B}$ antibodies, perinuclear antineutrophil cytoplasmic antibodies, and antineutrophil cytoplasmic antibodies was negative in all 11 patients. Brain biopsy in patient 1 was negative for vasculitis. Except for 1 groin pseudoaneurysm successfully treated with thrombin injection, there were no complications reported from the angiographic procedures.

All patients retrospectively met the angiographic criteria for treatment, and all territories treated met the criteria for an angiographic response. One patient required balloon angioplasty in addition to intra-arterial verapamil for severe ICA stenosis (patient 3). One patient who developed heparin-induced thrombocytopenia required the use of argatroban, a direct thrombin inhibitor, during her procedures (patient 4). All patients improved neurologically immediately following intra-arterial verapamil infusion, and all continued to show neurologic improvement on discharge. Four patients received and were unresponsive to steroids before the diagnosis of RCVS was considered. Five patients returned to the angiography suite multiple times because of recurrent symptoms or elevated transcranial Doppler studies (mean middle cerebral artery velocity greater than $120 \mathrm{~cm} / \mathrm{sec}$ or greater than 20 percent elevation of flow velocity above baseline). 
Table 2: Patient baseline characteristics, admission, treatment, and discharge metrics

\begin{tabular}{|c|c|c|c|c|c|c|}
\hline Case & $\begin{array}{c}\text { Age } \\
(\mathrm{yr}) / \mathrm{Sex}\end{array}$ & $\begin{array}{l}\text { Length of } \\
\text { Stay (Days) }\end{array}$ & $\begin{array}{l}\text { NIHSS (Admission/ } \\
\text { Discharge) }\end{array}$ & $\begin{array}{l}\text { IA Verapamil (No. of } \\
\text { Cycles/Total Amount) }\end{array}$ & $\begin{array}{c}\text { Follow-Up } \\
\text { Interval (Weeks) }\end{array}$ & $\begin{array}{l}\text { Follow-Up Imaging Results or } \\
\text { Clinical Examination }\end{array}$ \\
\hline 1 & $43 / \mathrm{F}$ & 19 & $16 / 1$ & $5 / 120 \mathrm{mg}$ & 16 & Resolution of vasoconstriction \\
\hline 2 & $43 / F$ & 17 & $0 / 0$ & $1 / 30 \mathrm{mg}$ & 1 & $\begin{array}{l}\text { Near-complete resolution of } \\
\text { vasoconstriction }\end{array}$ \\
\hline 3 & $25 / M$ & 14 & $2 / 0$ & $\begin{array}{l}\text { 2/40 mg, Balloon } \\
\text { angioplasty }\end{array}$ & 5 & Resolution of vasoconstriction \\
\hline 4 & $43 / F$ & 15 & $4 / 2$ & $2 / 55 \mathrm{mg}$ & 12 & mRS 1, cognitive delay, NIHSS 0 \\
\hline 5 & $35 / F$ & 11 & $2 / 0$ & $1 / 20 \mathrm{mg}$ & 1 & mRS 0 \\
\hline 6 & $25 / F$ & 3 & $0 / 0$ & $1 / 15 \mathrm{mg}$ & - & Lost to follow-up \\
\hline 7 & $27 / F$ & 6 & $4 / 1$ & $1 / 12.5 \mathrm{mg}$ & 1 & Resolution of vasoconstriction \\
\hline 8 & $33 / \mathrm{M}$ & 4 & $0 / 0$ & $1 / 10 \mathrm{mg}$ & - & Lost to follow-up \\
\hline 9 & $69 / F$ & 30 & $10 / 4$ & $3 / 60 \mathrm{mg}$ & 52 & $\begin{array}{l}\text { Died from multiple myeloma } \\
\text { complications }\end{array}$ \\
\hline 10 & $52 / F$ & 11 & $0 / 0$ & $1 / 10 \mathrm{mg}$ & 6 & Resolution of vasoconstriction \\
\hline 11 & $25 / F$ & 21 & $4 / 0$ & $6 / 180 \mathrm{mg}$ & - & Lost to follow-up \\
\hline
\end{tabular}

Note:-- indicates that no clinical or imaging follow-up was available.

\section{Case 1}

A 43-year-old woman developed thunderclap headache when she was running on the treadmill and went to an outside hospital where she had work-up for SAH, including CT of the head and lumbar puncture, which had negative findings. After a week, she developed acute worsening of headache with nausea and vomiting, and CT of the head at an outside hospital showed a right frontal hematoma. She was admitted to an outside hospital. MR imaging studies after 4 days showed right frontal hemorrhage, which was unchanged, and an MRA showed right ICA/MCA occlusion. At the outside hospital, she was treated with nimodipine and levetiracetam (Keppra), high-dose steroids, diazepam (Valium), and morphine. Her main symptoms were headache, confusion, and hallucinations; she also developed left hemivisual field inattention.

She was ultimately transferred to our hospital. On admission, her NIHSS score was 16, and she was found to have left-sided weakness, left hemianopia, and left hemiattention. MR imaging on admission showed multiple diffusion-restricted lesions in the bilateral hemispheres; however, lesions were more pronounced in the right hemisphere, particularly in the right MCA territory. DSA confirmed right ICA terminus occlusion extending into the right M1 segment with reconstitution of distal MCA branches via leptomeningeal collaterals. Multifocal vasoconstriction was seen in the left anterior circulation and was most severe in the bilateral posterior circulation (Fig 1). IA verapamil was injected in both ICAs (left ICA, $20 \mathrm{mg}$; right ICA, $5 \mathrm{mg}$ ) and the right vertebral artery $(10 \mathrm{mg})$, whereupon angiographic improvement was observed, particularly in the distal vessels (Fig 1), with the exception of the occluded right ICA/MCA. Because left-sided weakness and somnolence immediately improved, we presumed that the vasodilation led to improved leptomeningeal collateral flow to the right MCA territory. Oral verapamil was started and titrated to $240 \mathrm{mg}$ daily. Due to elevated transcranial sonography velocities or recurrent somnolence, IA verapamil treatment was repeated 4 additional times on hospital days 2, 3, and 4 for a total amount of $120 \mathrm{mg}$. Steroids were discontinued after a vasculitis work-up, including a brain biopsy negative for vasculitis. Other additional medications (mimodipine, morphine, diazepam, levetiracetam) were also stopped. With sustained clinical and sonographic improvement finally obtained, discharge occurred on day 19. The only residual symptom was a mild left neglect. Follow-up MRA at 4 months showed persistent occlusion of the right ICA terminus and right MCA, but complete resolution of vasoconstriction in the remaining intracranial circulation. At 5year follow-up, a slight weakness of the lower extremities and left lower quadrantanopia was still present.

\section{Case 2}

A 43-year-old woman presented at an outside hospital with headache and altered mental status; hypernatremia was found on laboratory work-up. She had a diagnosis of multiple sclerosis treated with interferon $\beta-1$ as well as a history of substance abuse and depression. MR imaging showed FLAIR signal alterations in both occipital and parietal lobes, consistent with posterior reversible encephalopathy syndrome, bilateral scattered foci of diffusion restriction, and demyelination consistent with multiple sclerosis. She was treated with oral verapamil and steroids and transferred to our hospital where DSA was performed for worsening confusion. It showed severe focal and segmental vasoconstriction in both the anterior and posterior circulations. A total amount of $30 \mathrm{mg}$ of IA verapamil was injected in both ICAs $(10 \mathrm{mg}$, respectively) and the left vertebral artery $(10 \mathrm{mg})$, which led to improvement of intracranial vessel caliber and improvement of symptoms. Follow-up CTA after 6 days showed only residual mild narrowing of the right distal M1 and proximal M2 branches. Encephalopathic symptoms resolved, steroid medication was stopped, and oral verapamil was continued. The patient was discharged to rehabilitation on day 17.

\section{Case 3}

A 25-year-old man presented with a partial right hemiparesis and intermittent aphasia following an episode of head trauma in the setting of a history of chronic binge drinking. The patient had known hypoparathyroidism, and on admission, he had elevated liver enzymes. He presented twice to an outside hospital, and ultimately CT and CTA were performed, which showed vasoconstriction. The patient was transferred to our hospital on day 10 post-trauma with motor weakness of the right leg, headache, and intermittent aphasia. MR imaging performed on hospital day 1 




FIG 1. DSA of patient 1 illustrates, in the left anterior circulation, diffuse vasoconstriction in peripheral MCA branches before verapamil infusion (arrows in A), which resolves following IA verapamil injection (B). The lower row shows occlusion of the right internal carotid terminus and a filiform caliber of the posterior cerebral artery, which arises from the left posterior communicating artery (C). The caliber increases markedly following verapamil injection, with some residual focal narrowing (arrows in D).

showed acute ischemia in the left anterior cerebral artery territory, bilateral SAH, a small amount of intraventricular hemorrhage, and severe narrowing of both ICA and the basilar artery (Fig 2). Endovascular treatment was performed on hospital day 2 in the morning with IA verapamil injection in the left ICA and basilar artery (10 mg, respectively), with improvement in the basilar narrowing (Fig 2). Due to agitation and fluctuating clinical status including transient aphasia during the procedure, the patient was intubated and taken to MR imaging, where no new ischemic lesions were identified. The patient returned to the angiography suite for uncomplicated angioplasty of the severe narrowing of the right ICA. Additionally, $10 \mathrm{mg}$ in the right ICA and, again, $10 \mathrm{mg}$ in the basilar artery were administered; overall, $40 \mathrm{mg}$ of verapamil was administered. After extubation, the clinical symptoms improved, oral nimodipine was started at $180 \mathrm{mg}$ per day, and the patient was placed in intensive care for 1 week. Oral nimodipine was discontinued on hospital day 12 due to resolution of symptoms. Twenty-four days had passed since the initial presentation, and discharge occurred on hospital day 14 to rehabilitation. Findings of an MRA at 5 weeks postdischarge were normal (Fig 2). 


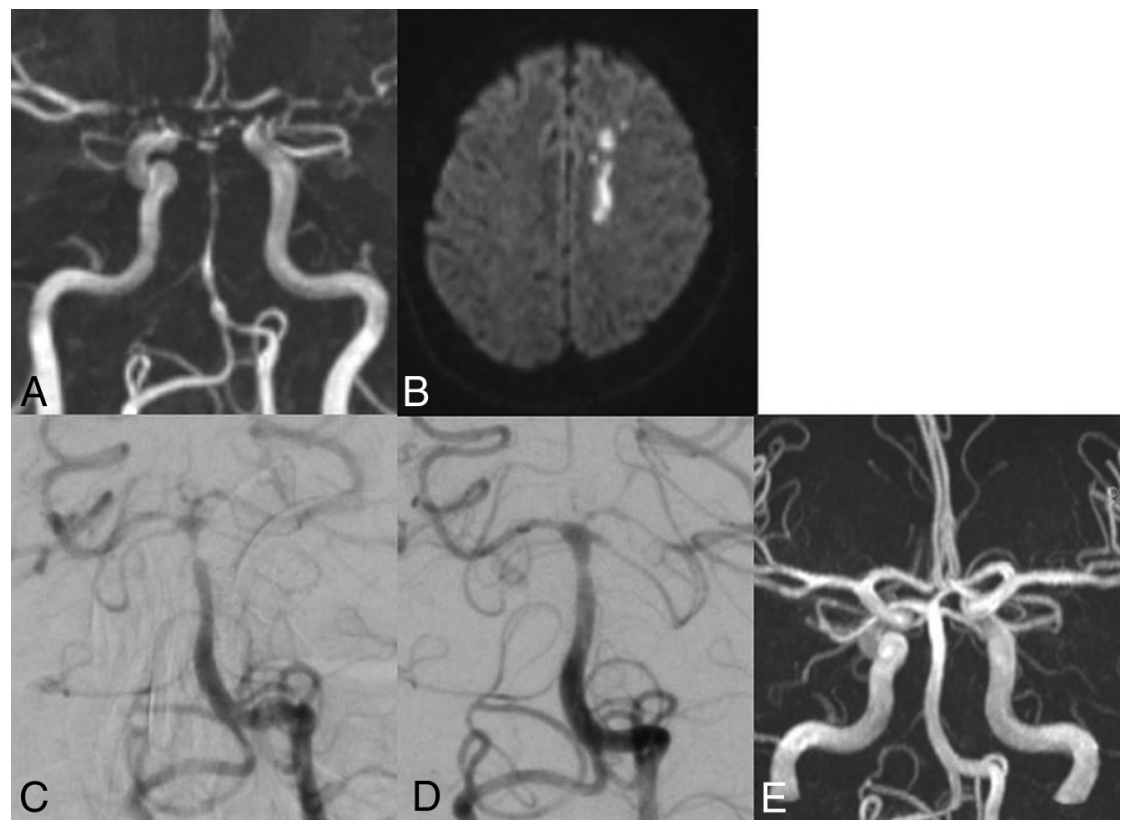

FIG 2. MRA of patient 3 on hospital day 1 shows severe vasoconstriction of the basilar artery as well as both ICA terminuses and M1 segments (A). Diffusion-weighted imaging reveals acute ischemia in the left anterior cerebral artery territory $(B)$. Angiogram on hospital day 2 shows severe distal basilar occlusion (C). One hour after infusion of $10 \mathrm{mg}$ of IA verapamil in the proximal left vertebral artery, the spasm is markedly reduced $(D)$. Follow-up MRA, 5 weeks after discharge, demonstrates complete resolution of vasoconstriction $(E)$.

\section{DISCUSSION}

In most cases, RCVS is a benign and self-limiting condition with spontaneous resolution; however, it can also be a complex clinicoradiologic challenge. ${ }^{4}$ Despite oral and intravenous calcium channel blockers, ${ }^{1,13-16}$ additional pathologic imaging features besides the typical "string of beads" appearance of vasoconstriction have been described in $12 \%-81 \%$ of patients. ${ }^{1}$ Unfortunately, the diagnosis is often delayed, and the initial clinical treatment is variable if not disorganized due to inexperience with the condition and its overlap with other disorders such as aneurysmal or nonaneurysmal SAH and vasculitis. RCVS can be easily mistaken for primary angiitis of the central nervous system even on digital subtraction angiography. Treatment options include medical optimization of risk factors, corticosteroids and oral or intra-arterial calcium channel blockers. The course can be monitored clinically and by using transcranial Doppler and complete resolution of vasoconstriction within 3 months is the typical confirmation for the diagnosis of RCVS.

All of our patients ultimately underwent IA treatment with verapamil due to their refractory, progressive clinical course. Our female preponderance and age range (25-69 years) reflect the predisposition of the syndrome for women (sex ratios from 2:1 up to $10: 1$ have been reported ${ }^{2,7,17}$ ) and the known predilection for young and middle-aged individuals, however, there are descriptions of RCVS in patients up to 76 years of age. .,7,18,19 $^{-1}$

In all of our patients, at least 1 imaging complication was present (acute ischemia: 8 patients; intraparenchymal hemorrhage: 3 patients; cortical SAH: 4 patients; posterior reversible encephalopathy syndrome: 2 patients). In the medical literature, up to $39 \%$ of the patients with RCVS have been reported to develop ischemic events, ${ }^{1}$ and $12 \%-$ $20 \%$ of patients were positive for intraparenchymal hemorrhage, ${ }^{7,14}$ slightly lower rates compared with our case series.

Cortical SAH has been described in up to $34 \%,{ }^{7,14}$ and posterior reversible encephalopathy syndrome, in $9 \%-38 \%$ of patients with RCVS. For the latter, vasoconstriction is believed to be causative for the characteristic vasogenic edema. ${ }^{7,20,21}$ Several authors have hypothesized that RCVS and posterior reversible encephalopathy syndrome have an overlapping pathophysiology because both occur in the setting of sympathetic overactivity and endothelial dysfunction leading to disturbances of the vascular tone. ${ }^{20,22,23}$

We observed clinical worsening in 4 of 11 patients despite empiric administration of glucocorticoids and/or cyclophosphamide. Empiric use of immunosuppressant therapy is common, given the clinical and angiographic similarities between primary angiitis of the central nervous system and RCVS and emphasizes the limited experience with this disease entity. ${ }^{17,24,25}$ Use of glucocorticoids in RCVS treatment has been described as associated with poor outcome and is therefore controversial. ${ }^{1,26-29}$ A possible explanation for deterioration following steroids is glucocorticoid-induced noradrenaline hypersensitivity in vascular smooth-muscle cells, though the exact mechanisms are not yet known. ${ }^{30}$

All our patients had at least 1 known RCVS trigger in their clinical history (autoimmune diseases: 3 patients; bone marrow transplantation: 2 patients; postpartum state: 2 patients; head trauma: 1 patient; exhaustive exercise/postcoital: 2 patients; blood transfusions: 1 patient; narcotic use/binge drinking: 5 patients). ${ }^{1}$ RCVS is known to be associated with autoimmune diseases and immunosuppressive treatment following transplantation. Endothelial damage and activation occur in both of these conditions and are believed to trigger the disease. ${ }^{1,31}$ While women are more predisposed to the disorder per se, the incidence rate in those who gave birth recently is even higher. ${ }^{1,32}$

Currently, there is no guideline for the use of IA treatment in RCVS. Nevertheless, IA treatment with calcium channel blockers has not only been recognized as an important treatment adjunct for severe refractory RCVS but has also been proposed as a differential diagnostic tool. ${ }^{8,9,27,33-36}$ At our institutions, there is an increased awareness of the entity in general and a lower threshold for intervention. As opposed to systemic administration of high-dose oral calcium channel blockers, this targeted therapy approach may avoid sustained hypotension, which can further precipitate cerebral infarction in the 
border zones. ${ }^{33}$ Slow injection rates of large doses and proximal IA administration of verapamil have been reported to be safe and effective in patients with vasospasm due to aneurysmal SAH in conjunction with monitored anesthesia care and were noted to be able to reduce the need for angioplasty in these cases. $^{11,37}$

Similar to the treatment of aneurysmal SAH-induced vasospasm, IA verapamil provided an improvement of the arterial caliber during angiographic studies, and all our patients demonstrated improvement clinically. This outcome can be interpreted as an early confirmation of the reversible nature of the vasoconstriction. Several authors have suggested that IA treatment might not only be an effective treatment option but may also serve as a diagnostic tool, crucial to guiding acute management. ${ }^{34,35}$ The improvement in vessel caliber is not angiographically immediate and is better observed at least 10 minutes after infusion. ${ }^{12}$ Furthermore, as with vasospasm from SAH, IA treatment is not durable and multiple treatments during the hospital course were necessary in 5 of 11 of our patients because the vasoconstriction tended to recur. Recurrence of vasoconstriction in this setting with the need for repeat IA treatment is not infrequent and has been reported. ${ }^{27}$ Nevertheless, there is evidence that in patients with vasospasm from $\mathrm{SAH}$, a preventative strategy using frequent and early endovascular treatment seems to reduce the risk of delayed cerebral ischemia. ${ }^{38}$

\section{CONCLUSIONS}

RCVS remains a challenging diagnosis, and its severity can be underestimated. Careful clinical and imaging evaluation is crucial, and a high index of suspicion for possible complications must be maintained to guide optimal management. Angiographic evaluation may be necessary in patients with fulminant RCVS, not only because of its superiority as the criterion standard for vascular imaging but also as a provocative diagnostic maneuver in the setting of potential IA treatment. This clinical report adds evidence for the effectiveness of IA verapamil as a treatment escalation in RCVS and confirms its favorable safety profile. In light of the growing evidence, we suggest a low threshold when considering IA verapamil injection not only as a therapeutic option but also as an early diagnostic tool for patients with oral treatmentrefractory presumed RCVS.

Disclosures: Richard Jung-UNRELATED: Travel/Accommodations/Meeting Expenses Unrelated to Activities Listed: Penumbra PEER Meeting, Comments: September 2829, 2018; attendance at a conference paid for by Penumbra.* *Money was paid to the individual.

\section{ACKNOWLEDGMENTS}

We thank Dr Selina Ackermann from the University Hospital Basel for editorial assistance.

\section{REFERENCES}

1. Ducros A. Reversible cerebral vasoconstriction syndrome. Lancet Neurol 2012;11:906-17 CrossRef Medline

2. Ducros A, Boukobza M, Porcher R, et al. The clinical and radiological spectrum of reversible cerebral vasoconstriction syndrome: a prospective series of 67 patients. Brain 2007;130:3091-3101 CrossRef Medline

3. Nowak DA, Rodiek SO, Henneken S, et al. Reversible segmental cerebral vasoconstriction (Call-Fleming syndrome): are calcium channel inhibitors a potential treatment option? Cephalalgia 2003;23:218-22 CrossRef Medline

4. Calabrese LH, Dodick DW, Schwedt TJ, et al. Narrative review: reversible cerebral vasoconstriction syndromes. Ann Intern Med 2007;146:34-44 CrossRef Medline

5. Chen SP, Fuh JL, Chang FC, et al. Transcranial color Doppler study for reversible cerebral vasoconstriction syndromes. Ann Neurol 2008;63:751-57 CrossRef Medline

6. Singhal AB, Topcuoglu MA, Fok JW, et al. Reversible cerebral vasoconstriction syndromes and primary angiitis of the central nervous system: clinical, imaging, and angiographic comparison. Ann Neurol 2016;79:882-94 CrossRef Medline

7. Singhal AB, Hajj-Ali RA, Topcuoglu MA, et al. Reversible cerebral vasoconstriction syndromes: analysis of 139 cases. Arch Neurol 2011;68:1005-12 CrossRef Medline

8. Elstner M, Linn J, Muller-Schunk S, et al. Reversible cerebral vasoconstriction syndrome: a complicated clinical course treated with intra-arterial application of nimodipine. Cephalalgia 2009;29:67782 CrossRef Medline

9. Al-Mufti F, Dodson V, Wajswol E, et al. Chemical angioplasty for medically refractory reversible cerebral vasoconstriction syndrome. Br J Neurosurg 2018;32:431-35 CrossRef Medline

10. Jun P, Ko NU, English JD, et al. Endovascular treatment of medically refractory cerebral vasospasm following aneurysmal subarachnoid hemorrhage. AJNR Am J Neuroradiol 2010;31:1911-16 CrossRef Medline

11. Keuskamp J, Murali R, Chao KH. High-dose intraarterial verapamil in the treatment of cerebral vasospasm after aneurysmal subarachnoid hemorrhage. J Neurosurg 2008;108:458-63 CrossRef Medline

12. Sehy JV, Holloway WE, Lin SP, et al. Improvement in angiographic cerebral vasospasm after intra-arterial verapamil administration. AJNR Am J Neuroradiol 2010;31:1923-28 CrossRef Medline

13. Ansari SA, Rath TJ, Gandhi D. Reversible cerebral vasoconstriction syndromes presenting with subarachnoid hemorrhage: a case series. J NeuroInterv Surg 2011;3:272-78 CrossRef Medline

14. Ducros A, Fiedler U, Porcher R, et al. Hemorrhagic manifestations of reversible cerebral vasoconstriction syndrome: frequency, features, and risk factors. Stroke 2010;41:2505-11 CrossRef Medline

15. Sattar A, Manousakis G, Jensen MB. Systematic review of reversible cerebral vasoconstriction syndrome. Expert Rev Cardiovasc Ther 2010;8:1417-21 CrossRef Medline

16. Noda K, Fukae J, Fujishima K, et al. Reversible cerebral vasoconstriction syndrome presenting as subarachnoid hemorrhage, reversible posterior leukoencephalopathy, and cerebral infarction. Intern Med 2011;50:1227-33 CrossRef Medline

17. Chen SP, Fuh JL, Lirng JF, et al. Recurrent primary thunderclap headache and benign CNS angiopathy: spectra of the same disorder? Neurology 2006;67:2164-69 CrossRef Medline

18. Cappelen-Smith C, Calic Z, Cordato D. Reversible cerebral vasoconstriction syndrome: recognition and treatment. Curr Treat Options Neurol 2017;19:21 CrossRef Medline

19. Ducros A, Wolff V. The typical thunderclap headache of reversible cerebral vasoconstriction syndrome and its various triggers. Headache 2016;56:657-63 CrossRef Medline

20. Bartynski WS. Posterior reversible encephalopathy syndrome, Part 2: controversies surrounding pathophysiology of vasogenic edema. AJNR Am J Neuroradiol 2008;29:1043-49 CrossRef Medline

21. Chen SP, Fuh JL, Wang SJ, et al. Magnetic resonance angiography in reversible cerebral vasoconstriction syndromes. Ann Neurol 2010;67:648-56 CrossRef Medline

22. Bartynski WS, Boardman JF. Catheter angiography, MR angiography, and MR perfusion in posterior reversible encephalopathy syndrome. AJNR Am J Neuroradiol 2008;29:447-55 CrossRef Medline 
23. Chen SP, Yang AC, Fuh JL, et al. Autonomic dysfunction in reversible cerebral vasoconstriction syndromes. J Headache Pain 2013;14:94 CrossRef Medline

24. Calabrese LH, Gragg LA, Furlan AJ. Benign angiopathy: a distinct subset of angiographically defined primary angiitis of the central nervous system. J Rheumatol 1993;20:2046-50 Medline

25. Kadkhodayan Y, Alreshaid A, Moran CJ, et al. Primary angiitis of the central nervous system at conventional angiography. Radiology 2004;233:878-82 CrossRef Medline

26. Chen SP, Fuh JL, Wang SJ. Reversible cerebral vasoconstriction syndrome: current and future perspectives. Expert Rev Neurother 2011;11:1265-76 CrossRef Medline

27. French KF, Hoesch RE, Allred J, et al. Repetitive use of intra-arterial verapamil in the treatment of reversible cerebral vasoconstriction syndrome. J Clin Neurosci 2012;19:174-76 CrossRef Medline

28. Katz BS, Fugate JE, Ameriso SF, et al. Clinical worsening in reversible cerebral vasoconstriction syndrome. JAMA Neurol 2014;71:6873 CrossRef Medline

29. Singhal AB, Topcuoglu MA. Glucocorticoid-associated worsening in reversible cerebral vasoconstriction syndrome. Neurology 2017;88:228-36 CrossRef Medline

30. Rascher W, Dietz R, Schomig A, et al. Modulation of sympathetic vascular tone by prostaglandins in corticosterone-induced hypertension in rats. Clin Sci 1979;57(Suppl 5):235s-37s. CrossRef Medline

31. Leroux G, Sellam J, Costedoat-Chalumeau N, et al. Posterior reversible encephalopathy syndrome during systemic lupus erythematosus: four new cases and review of the literature. Lupus 2008;17:139-47 CrossRef Medline

32. Kumai Y, Seguchi O, Sato T, et al. Reversible cerebral vasoconstriction syndrome after heart transplantation: a case report. Transplant Proc 2017;49:2415-18 CrossRef Medline

33. Farid H, Tatum JK, Wong C, et al. Reversible cerebral vasoconstriction syndrome: treatment with combined intra-arterial verapamil infusion and intracranial angioplasty. AJNR Am J Neuroradiol 2011;32:E184-87 CrossRef Medline

34. Laneuville $M$, Ding J, Shamy $M$, et al. Intra-arterial milrinone may differentiate fulminant RCVS from vasculitis. Neurology 2017;89:109394 CrossRef Medline

35. Linn J, Fesl G, Ottomeyer C, et al. Intra-arterial application of nimodipine in reversible cerebral vasoconstriction syndrome: a diagnostic tool in select cases? Cephalalgia 2011;31:1074-81 CrossRef Medline

36. Bouchard M, Verreault S, Gariepy JL, et al. Intra-arterial milrinone for reversible cerebral vasoconstriction syndrome. Headache 2009;49:142-45 CrossRef Medline

37. Albanese E, Russo A, Quiroga M, et al. Ultrahigh-dose intraarterial infusion of verapamil through an indwelling microcatheter for medically refractory severe vasospasm: initial experience. Clinical article. J Neurosurg 2010;113:913-22 CrossRef Medline

38. Jabbarli R, Pierscianek D, Rolz R, et al. Endovascular treatment of cerebral vasospasm after subarachnoid hemorrhage: more is more. Neurology 2019;93:e458-66 CrossRef Medline 